\title{
Linking top-down and bottom-up processes through the new U.S. National Ocean Policy
}

\author{
Leila Sievanen ${ }^{1}$, Heather M. Leslie ${ }^{2}$, Julia M. Wondolleck ${ }^{3}$, Steven L. Yaffee ${ }^{4}$, Karen L. McLeod ${ }^{5}$, \\ \& Lisa M. Campbell ${ }^{6}$ \\ 1 Center for Environmental Studies, Box 1943, Brown University, Providence, RI 02912, USA \\ 2 Center for Environmental Studies and Department of Ecology \& Evolutionary Biology, Box 1943, Brown University, Providence, RI 02912, USA \\ 3 School of Natural Resources and Environment, University of Michigan, 3512 Dana Building, 440 Church St, Ann Arbor, MI 48109, USA \\ ${ }^{4}$ School of Natural Resources and Environment, University of Michigan, 3522 Dana Building, 440 Church St, Ann Arbor, MI 48109, USA \\ ${ }^{5}$ COMPASS, Oregon State University, Department of Zoology, 3029 Cordley Hall, Corvallis, OR 97331, USA \\ ${ }^{6}$ Nicholas School of Environment, Duke University, BRL 309 DUML, 135 Duke Marine Lab Rd., Beaufort, NC 28516, USA
}

\section{Keywords}

Ecosystem-based management; marine conservation; marine management; marine policy; marine spatial planning; National Ocean Policy.

\section{Correspondence}

Leila Sievanen, Center for Environmental

Studies, Box 1943, Brown University,

Providence, RI 02912, USA. Tel: 401-863-6897;

fax: 401-863-3503.

E-mail: Leila_Sievanen@brown.edu

Received

17 October 2010

Accepted

24 February 2011

Editor

Sarah Pralle

doi: 10.1111/j.1755-263X.2011.00178.x

\begin{abstract}
Two of the priority objectives in the new U.S. National Ocean Policy are "ecosystem-based management" (EBM) and "coastal and marine spatial planning" (CMSP). Drawing from several studies demonstrating these concepts in practice in the United States and elsewhere, we provide recommendations for those engaged in implementing the new policy. We describe the types of strategic policy actions and management choices currently being used in ecosystembased management efforts to provide opportunities for learning and problemsolving, enable capacity for action, and enhance coordination among existing initiatives. We show that implementation of this ambitious national policy at local to regional scales-where people are most closely linked with coastal and marine systems-will require close attention to these social, political, and institutional issues, as well as to ecological constraints and objectives.
\end{abstract}

\section{Introduction}

In the face of continued marine pollution, biodiversity loss, coastal development, increasing interest in new ocean uses such as wind and wave energy, and concerns about climate change, a National Ocean Policy was established in the United States on July 19, 2010 to develop a proactive, comprehensive, and participatory framework for ecosystem-based ocean stewardship and management (E. O. 13547). The new U.S. National Ocean Policy provides a much-needed, high-level policy framework that addresses the "failure of governance" (Lubchenco \& Sutley 2010) that has either stymied or simply not encouraged comprehensive and deliberate stewardship of the marine environment. It is a top-down directive that establishes national and regional ocean councils, mandates the use of ecosystem-based approaches including coastal and marine spatial planning, and requires annual reporting of activities and accomplishments by federal agencies. It is a critical step forward, establishing a comprehensive policy where one did not previously exist. Parallel efforts are developing in states such as Massachusetts and California and in the legal structures of other countries, including Canada's Oceans Act. Given such a strong and complementary set of efforts to reform ocean policy, it is important to learn from these experiences in order to design effective policies and institutional arrangements, and identify implementation strategies to facilitate achieving the goals of the new U.S. National Ocean Policy. 
Here we report key observations from multiple studies of the experiences of over 25 marine initiatives that incorporated ecosystem-based management approaches, including, in some cases, coastal and marine spatial planning. Ecosystem-based management (EBM) is an integrated approach to management that considers the entire ecosystem, including humans (Yaffee 1996; McLeod \& Leslie 2009). The core goal of EBM is to sustain the long-term capacity of these systems to deliver a range of ecosystem services, with a focus on ecosystem health and human well-being (McLeod et al. 2005). EBM differs from current approaches that usually focus on a single species or type of activity. Instead, management plans and strategies incorporate the cumulative impacts of multiple activities on entire ecosystems. Ultimately, EBM requires (1) a common, overarching, ecosystem-level goal, (2) explicit ways of assessing tradeoffs among multiple objectives, and (3) opportunities for learning and adaptation. Coastal and marine spatial planning (CMSP) is a comprehensive, adaptive, integrated, and transparent spatial planning process, based on sound science, for analyzing current and anticipated uses of ocean, coastal, and Great Lakes areas. CMSP identifies areas most suitable for various types or classes of activities in order to reduce conflicts among uses, reduce environmental impacts, facilitate compatible uses, and preserve critical ecosystem services to meet economic, environmental, security, and social objectives (Ehler \& Douvere 2009; CEQ 2010).

Our studies have used semistructured interviews, document analysis, and in-depth case studies. Many of the examples are drawn from a set of 27 case studies that were the subject of a 2-year investigation. In the interest of brevity, we do not provide details of the case studies here. Extensive narratives of each case and cross-cutting lessons learned for EBM and CMSP will be featured on a website (www.snre.umich.edu/emi/mebm) to be launched in mid 2011. This website will feature the 27 case studies as well as summaries of 30 additional cases. The cases show how various marine EBM projects were initiated, engaged diverse stakeholders, bridged multiple jurisdictions, conducted research and monitoring efforts, implemented CMSP and other ecosystem-based approaches. While all cases inform the insights we share here, we highlight examples from the 15 U.S. cases, given the opportunity to inform policy development in that context.

\section{Linking top-down with bottom-up efforts}

Marine EBM initiatives often are based on the planning unit of the "ecosystem" rather than political or administrative units, and thus require coordination between multiple agencies, jurisdictions, and communities. Existing initiatives have pursued a range of approaches to bridge regulatory and nonregulatory processes, long-standing and nascent initiatives, and multiple levels and scales. This article will not discuss the full range of these linkages. As our aim is to provide lessons regarding how the new national policy can enable and encourage new and existing efforts, here we focus on how existing successful EBM initiatives have combined top-down and bottom-up strategies.

The success of policies emerging from higher levelslike the National Ocean Policy-requires enabling a mix of strategies along a spectrum from formal authority (whether federal, state, or local) to informal motivations to collaborate (often building on a sense of place or an economic or cultural stake). We use the terms "top-down" to mean formal authority and "bottom-up" to mean informal motivation. We do not use the terms in the dichotomous sense of large-scale and government-led versus small-scale and community-led. Indeed, in many of the cases we examined, nonlegally binding cooperative efforts occur on large scales such as the Gulf of Maine Council, and many government-sponsored efforts, such as the National Estuary Program (NEP), have no formal authority and are purely voluntary.

Policy-makers are in a position to provide top-down incentives, legitimacy, and authority that enable and encourage new and existing efforts. Below we highlight how the implementation of the new National Ocean Policy, such as through drafting of the nine strategic action plans (Federal Register Notice 2011-1316, 1/2011)can capitalize on the lessons learned from top-down and bottom-up strategies pursued to date.

\section{Recommendations for implementing the U.S. National Ocean Policy}

First, Provide Opportunities for Learning and Problem-Solving. All of our cases demonstrate the simple yet essential role that a "meeting place" plays, both literally and figuratively, in building relationships, enabling learning and problem-solving, and linking different jurisdictions and authorities. Simply put, people work together when they are together. Marine EBM initiatives have adopted a number of institutional innovations that should be promoted including collaborative scientific efforts, advisory councils, and nested institutional arrangements.

\section{Collaborative fact-finding efforts}

While policy decisions have traditionally been highly influenced by the advice of experts, the credibility of 
scientific expertise has been contested for decades, particularly in fisheries management. In many cases, centralized top-down fisheries management has been blamed for both ecological failures and socioeconomic hardships. Tensions between fishing communities, scientists, and managers are common. In some cases, these tensions result partly from fishers' perceptions that the data produced by scientists do not match their experiential knowledge based on their interactions with the resource. In response to these tensions, a few of the marine EBM efforts are experimenting with collaborative research between fishers and scientists. In Morro Bay (CA), managers are employing what Wilson (1999) has coined the "community science" model of collaboration (Wendt \& Starr 2009). This model recognizes that fishers and scientists will hold competing constructions of the resource base but that collaboration can still happen through open communication, participation, and collaborative fact-finding efforts. Using a fully collaborative approach (NRC 2004), fishers are involved in all phases of the research process-framing of the issues and concerns, forming research questions and hypotheses, and interpreting the data. In the Northwest Straits (WA), scientists and citizens are working together in innovative ways to better understand the Puget Sound ecosystem and to identify community-level restoration projects. While these collaborations are not instant solutions to tensions between fishing communities, scientists, and managers, the extent to which those affected by decisions participate in the generation of knowledge and decision-making processes can help to develop trust among these actors and to strengthen legitimacy of the process and increase compliance (Wondolleck \& Yaffee 2000; Izeta \& Wilson 2006; Feeney et al. 2010), particularly if those affected see new rules as reasonable within the local context (Jentoft 2000).

\section{Advisory councils}

Community representatives, user groups, elected officials, and other agency representatives should collaborate to set objectives at an early stage. Standing Committees or Advisory Councils have served an important function in a number of our cases, bringing a diverse spectrum of parties together on a regular basis to assess and discuss issues, resolve conflicts, monitor resources, and provide advice. For example, the first attempt in 1999 by the California Department of Fish and Game to implement the Marine Life Protection Act (MLPA) to improve the marine protected area (MPA) network along the California coast conformed to a top-down approach. The public resisted these efforts. (Similar reactions have occurred to top-down impositions of MPAs in the North- west Straits, Florida, and Delaware). It was not until a multistakeholder collaborative process was used in the third attempt to implement the MLPA that MPAs were established along the California coast. Incorporating a range of interests early can ensure that conservation priorities set at higher levels are not at odds with local priorities and preexisting initiatives.

\section{Nested institutional arrangements}

The concept of "nesting" recognizes that there will be different levels of decision-making from top-down legal frameworks that regulate and constrain activities to bottom-up day-to-day rules controlling resource management (Ostrom 1990). The current institutional structure regulating coastal and ocean-related activities in the United States often does not match the scales at which key ecological, social, and economic dynamics operate (Wilson 2006; Leslie \& McLeod 2007). While ocean ecosystems operate at multiple scales, human activities, like fisheries and energy development, are often managed at a single, geographically broad scale. For example, the coast-wide management scale of the New England and West Coast groundfish fisheries does not match the finer scale ecological, social, and economic heterogeneity of these coupled human and natural systems (Wilson 2006; Gunderson et al. 2008; Francis et al. 2009). While many recognize the need for multiscale institutions that mirror the spatial organizations of ecosystem, as well as human patterns of use, this is difficult in practice. Several of the marine EBM efforts, such as Morro Bay (CA) and Port Orford (OR), are creating fine-scale knowledge better adapted to ecological and social scales of activity, as communities become more involved in scientific assessment and monitoring of local resources (Francis et al. 2009; Wendt \& Starr 2009). In the northeast U.S., the Gulf of Maine Council brings together representatives of government, resource user groups, science and civil society to maintain and enhance environmental quality in the Gulf to allow for sustainable resource use by existing and future generations (GoMC 2011). Although it has no regulatory authority, the Council's ability to convene representatives from three U.S. states and two Canadian provinces and connect with more local scale initiatives has enabled development of common goals and collaborative projects. This kind of nested approach, with associated high user participation and integration with larger-scale research and management activities, can help to match the spatial scales of biological populations, ecological communities, and human communities for particular management issues. The regional planning bodies that will be convened under the new national policy could provide an opportunity to better coordinate and support similar multiscale management efforts. 
Second, Encourage Capacity for Action. In many ecosystem-based approaches, planning occurs at large spatial scales that involve many organizations and agencies. Because action occurs by individuals and organizations in specific places, the crux of these approaches lies in the juncture when planning ends and action begins (Dietz et al. 2003; Agardy 2005; Crowder et al. 2006; Young et al. 2007). Incentives for action include economic and noneconomic approaches such as federal restoration programs, payments for ecosystem services, and learning networks.

\section{Economic approaches}

In some cases, conservation and management priorities set at higher levels are ambitious with no financial support. The provision of top-down incentives in the form of funding for ecosystem-scale activities can motivate organizations and individuals to take action. Existing programs, such as the NEP and federal restoration programs, and emerging opportunities, such as payments for ecosystem services and ocean energy and carbon taxes, can help to underwrite development of a shared information base, create small successes that motivate action, and enable the multiparty communication and negotiation that are at the heart of these processes. For example, in Morro Bay, California, new monetary resources and emphasis on the watershed scale provided by the NEP facilitated the development of a local network composed of local government officials, private citizens, and representatives from other federal agencies, academic institutions, industry, and estuary user-groups who worked together to identify problems in the estuary, develop specific actions to address those problems, and create and implement a formal management plan to restore and protect the estuary.

\section{Social and institutional approaches}

On-the-ground progress is facilitated by a range of factors other than funding. Building on a sense of crisis or a shared commitment to a specific place was often powerful. For example, in response to increased top-down restrictions that contributed to the loss of fisheries-related employment, the remote fishing community of Port Orford, Oregon, realized that local livelihoods could only be sustained through management activities that reflected ecosystem dynamics. Also, agency managers from New England states and Canadian provinces in the Gulf of Maine Council recognized their shared concern and responsibility for an increasingly stressed Gulf of Maine ecosystem and voluntarily organized to begin advancing EBM objectives there. Additionally, the presence of ded- icated, charismatic champions of EBM in the San Juan Islands of Washington State played a central role in catalyzing initiatives. Political will was one of the most significant factors facilitating action. At times, high-level officials' endorsement of marine EBM was critical to push projects forward; Florida Governor Jeb Bush's leadership resurrected a floundering Gulf of Mexico marine EBM initiative, drawing the engagement and sustained commitment of his counterparts in the four other Gulf States. In contrast, bottom-up action was stymied in other cases by opposition or inattention by leaders.

It also helps to have a cadre of agency individuals and stakeholder groups trained both in collaboration and the science underlying ecosystem-scale action, and able to facilitate complex decision making processes. Trainings and convenings can provide a basis for development of relationships and trust that are critical to forward progress. Additionally, they can build critical networks that can help sustain marine EBM efforts. In interviews, many managers expressed that they felt isolated and unaware of what others were experiencing and accomplishing. "We felt very alone," commented one manager; "We live in a remote area on the coast, in a little town, and we need to know other people are doing this and to learn from them." The West Coast EBM Network provides an important support function for its six partner groups. Network participants repeatedly expressed that the collaboration, information-sharing, and support that the Network provides has been a major asset to their own EBM and community-based projects.

Third, Build on Current Initiatives. By embracing many pathways toward marine EBM, an adaptive and evidence-based process can be used to move the science and practice of marine EBM forward. As the U.S. CMSP framework (as described in CEQ 2010) is further developed and implemented by the Obama administration, particular effort should be made to encourage innovation and regional differentiation.

There is an impressive array of marine EBM-related activity occurring throughout the United States today; this reality begs both caution and encouragement. Caution is warranted so as not to take the wind out of the sails of these existing initiatives. In a number of our cases, managers mentioned the fatigue, diminishing focus and accomplishment and, at times, demoralization when their efforts were "transformed" by a new administration's priorities and directives. In Morro Bay, some managers of the existing NEP process initially perceived the EBM project as a redirection of their efforts rather than a productive integration, which created a somewhat rocky start for the project. This was later smoothed out through further collaboration, communication, and increased recognition of shared interests. New governors' 
successive initiatives can both elevate and invigorate marine EBM activities but they can also consume time, energy, resources and, sometimes, enthusiasm as those involved regroup, reorganize, and begin anew. For example, in Washington State the salmon recovery program was replaced by the "Shared Strategy" which was then replaced by the "Puget Sound Partnership." One manager, a central player in several Puget Sound initiatives, retired early because he could not endure yet another organizational transition. Similarly, the Gulf of Maine Council is beginning to feel the effects of the Northeast Regional Ocean Council (NROC) as its U.S. members now have less time and fewer resources to participate in both initiatives. This issue of organizational fatigue and overlap is not trivial and decision makers will need to confront it as the regional planning bodies form in the coming months.

The take-away lesson of this article is that there are numerous initiatives to link to and build upon, but care needs to be taken to ensure that doing so enhances or complements the efforts, and does not undermine them. Decision makers and stakeholders from the local to federal levels are moving quickly to implement the new National Ocean Policy, and coastal and marine spatial planning and other ecosystem-based approaches are central to these efforts. These principles reinforce the need for new research and synthesis by biophysical and social scientists to better understand social-ecological linkages; collection of information at finer spatial scales; and multiscale institutions that are cognizant of variable social, ecological, and economic scales. We have described the types of innovations already in use by ecosystem-based initiatives to achieve similar aims in the United States. Encouraging learning networks, advisory councils, and institutional nesting can facilitate social learning, provide feedback regarding pertinent federal legislation, and sustain these efforts.

\section{Acknowledgments}

We gratefully acknowledge support from the David and Lucile Packard Foundation and thank the project staff and partners that graciously collaborated with us in this research. A special thanks to A. Barker, C. Elliott, M. Fainter, T. Gancos, D. Gershman, M. Griffis, R. Gruby, C. Hume, J. Johnson, S. McKearnan, A. Samples, S. Tomsky and C. Villanueva for help with gathering and processing data.

\section{References}

Agardy, T. (2005) Global marine conservation policy versus site-level: the mismatch of scale and its implications. Mar Ecol Prog Ser 300, 242-248.
CEQ (The White House Council on Environmental Quality). (2010) Final recommendations of the Interagency Ocean Policy Task Force. July 19. Available from: http://www. whitehouse.gov/files/documents/OPTF_FinalRecs.pdf. Accessed 2 February 2011.

Crowder, L.B., Osherenko G., Young O.R. et al. (2006) Resolving mismatches in U.S. ocean governance. Science 313, 617-618.

Dietz, T., Ostrom E., Stern P.C. (2003) The struggle to govern the commons. Science 302, 1907-1912.

Ehler, C., Douvere F. (2009) Marine spatial planning: a step-by-step approach toward ecosystem-based management. Intergovernmental Oceanographic Commission and Man and the Biosphere Programme. IOC Manual and Guides, 53, 6, Paris, UNESCO.

Executive Order 13547. (2010) Stewardship of the ocean, our coasts, and the great lakes. President Barack Obama, Office of the Press Secretary. July 19, 2010.

Federal Register Notice 2011-1316. (2011) National Ocean Council; Development of strategic action plans for the National Policy for the Stewardship of the Ocean, Our Coasts, and the Great Lakes, 4139-4141. January 2011.

Feeney, R.G., La Valley K.J., Hall-Arber M. (2010) Assessing stakeholder perspectives on the impacts of a decade of collaborative fisheries research in the Gulf of Maine and Georges Bank. Mar Coast Fisher Dyn, Manage, Ecosyst Sci 2, 205-216.

Francis, R.C., Little J.E., Bloeser J.A. (2009) Matching spatial scales of ecology, economy, and management for groundfish of the U.S. West Coast marine ecosystem: a state of the science review. A report to the Lensfest Ocean Program at the Pew Charitable Trusts.

GoMC (Gulf of Maine Council on the Marine Environment). (2011) Available from: http://www.gulfofmaine.org/. Accessed 2 February 2011.

Gunderson, D.R., Parma A.M., Hilborn R. et al. (2008) The challenge of managing nearshore rocky reef resources. Fisheries 33, 172-179.

Izeta, L.M., Wilson D.C. (2006) The knowledge base for fisheries management. Elsevier, Amsterdam.

Jentoft, S. (2000) Legitimacy and disappointment in fisheries management. Mar Pol 24,141-148.

Leslie, H.M., McLeod K.L. (2007) Confronting the challenges of implementing marine ecosystem-based management. Front Ecol Environ 5, 540-548.

Lubchenco, J., Sutley N. (2010) Policy forum: proposed US policy for ocean, coast and Great Lakes stewardship. Science 328, 1485-1486.

McLeod, K.L., Leslie H.M. (2009) Ecosystem-based management for the oceans. Island Press, Washington, DC.

McLeod, K.L., Lubchenco J., Palumbi S.R., Rosenberg A.A. (2005) Scientific consensus statement on marine ecosystem-based management. Signed by 221 academic scientists and policy experts with relevant expertise and published by the Communication Partnership for Science 
and the Sea. Available from: http://compassonline.org/?q= EBM. Accessed 1 February 2011.

NRC (National Research Council). (2004) Cooperative research in the National Marine Fisheries Service. National Academies Press, Washington, DC.

Ostrom, E. (1990) Governing the commons: the evolution of institutions for collective action. Cambridge University Press, New York.

Wendt, D.E., Starr R.M. (2009) Collaborative research: an effective way to collect data for stock assessments and evaluate marine protected areas in California. Mar Coast Fisher Dyn, Manage, Ecosyst Sci 1, 315-324.

Wilson, D.C. (1999) Fisheries science collaborations: the critical role of the community. Conference on holistic management and the role of fisheries and mariculture in the coastal community, 11-13 November 1999, Tjärnö Marine Biological Laboratory, Sweden.

Wilson, J.A. (2006) Matching social and ecological systems in complex ocean fisheries. Ecol Soc 11, 9-30.

Wondolleck, J.M., Yaffee S.L. (2000) Making collaboration work. Island Press, Washington, DC.

Yaffee, S.L., Phillips A., Frentz I., Hardy P., Maleki S., Thorpe B. (1996) Ecosystem management in the United States: an assessment of current experience. Island Press, Washington, DC.

Young, O.R., Osherenko G., Ekstrom J. et al. (2007) Solving the crisis in ocean governance: Place-based management of marine ecosystems. Environment 49, 20-32. 